\title{
Effect of Clinical Nurses Specialists intervention on rehabilitation outcomes in patients with heart failure
}

\author{
Palle Larsen ${ }^{* 1}$, Thordis Thomsen ${ }^{2}$, Preben U Pedersen ${ }^{3}$ \\ ${ }^{1}$ Danish Centre of Systematic Review, Clearing House, Aalborg University, Denmark \\ ${ }^{2}$ Rigshospitalet, Copenhagen University Hospital, Denmark \\ ${ }^{3}$ Centre of Clinical Guidelines, Clearing House, Aalborg University, Denmark
}

Received: October 1, 2014

Accepted: December 15, 2014 Online Published: December 29, 2014

DOI: $10.5430 /$ cns.v3n2p31

URL: http://dx.doi.org/10.5430/cns.v3n2p31

\begin{abstract}
Introduction: Living with heart failure is serious and call for long term rehabilitation care. Rehabilitation elements for patients with Heart Failure are based on the recommendations from the European Society of Cardiology and focuses on self-care and adherence in general. The aim of this study was, therefore, to test a protocol for rehabilitation of patients after completing rehabilitation in the outpatient clinic.
\end{abstract}

Method: The study design is quasi-experimental. Patients in the control group follow the conventional rehabilitation. For the patients in the intervention group an individual rehabilitation plan was prepared and followed up by telephone after 4 and 12 weeks. For all patients Health Status were measured with Short Form 36 and EQ5D.

Results: One hundred and sixty-two patients are included in the study of which $137(84.6 \%)$ consented. There were no differences in total self-care behavior between the groups at baseline and at follow-up after 4 and 12 weeks. Within the control group no changes in the self-care score from baseline to follow-up were observed. Total EQ5D scores showed no significant differences between the groups at baseline. Subgroup analyses showed a significant difference in usual activities and decrease in anxiety/depression in the intervention group with a within-group increase from 34.4 percent at baseline to 51.4 percent after 12 weeks $(p=.0002)$. No between-groups differences at 4 weeks or 12 weeks were observed.

Conclusion: No significant increase in Health Status between groups were found. Subgroup analysis showed a significant within-group decrease in development of anxiety in the intervention group from baseline to twelve weeks. There may be a correlation between the increase in self-care behavior in patients in the intervention group after 12 weeks and a reduction in anxiety.

Key Words: Heart failure patients, Health status, Rehabilitation

\section{Introduction}

In Europe the prevalence of Heart Failure (HF) is estimated to be $2 \%-3 \%$ of the population and the number of people with $\mathrm{HF}$ is expected to increase over the next decade. ${ }^{[1]} \mathrm{HF}$ is a progressing and invalidating disease leading to frequent hospital admissions and decline in quality of life. The five

*Correspondence: Palle Larsen; Email: pla@kliniskeretningslinjer.dk; Address: Danish Centre of Systematic Review, Clearing House, Aalborg University, Denmark. 
year mortality rate is nearly $70 \% .{ }^{[2]}$ Adherence to pharmacological and non-pharmacological advices can reduce the progression of the disease and decline in patients' Health Status in everyday life. In order to slow down the progression of the disease patients need to address general cardiovascular risk factors, have insight into the expected consequences of the disease and management of symptoms and their impact on daily life. Increasing patients' self-care ability is emphasized as an important intervention to increase adherence to treatment, improve outcome of rehabilitation and reduce costs for the health care sector. ${ }^{[3-8]}$

In order to achieve the best outcome of cardiac rehabilitation tailored interventions should be carried out during the hospital stay (phase one), during visits in out-patients clinics (phase two), and, finally, during the transition to outpatient rehabilitation (phase three). Multidisciplinary or nurse lead rehabilitation carried out during the acute hospital stay and in out-patients clinics have been shown to increase patients' self-care ability and patients' management of everyday life with HF. ${ }^{[9-18]}$ No studies have tested whether further improvement in the outcome of rehabilitation can be obtained if patients are supported during the transition from phase two to phase three in their rehabilitation. In general, there is little evidence for the effect of rehabilitation interventions after discharge from outpatient clinics. ${ }^{[19]}$

Worldwide there is a need for developing effective educational interventions ${ }^{[20]}$ as only 20 to $60 \%$ of patients with $\mathrm{HF}^{[21,22]}$ adhere to advice from health care professionals. No single intervention seems to be effective in increasing adherence and to support patients in making adequate behavioral changes during rehabilitation. Combinations of several methods seem to be most effective and when the aim is to motivate patients to improve self-care behaviour. Selfcare has been used as an outcome of rehabilitation but not as a means to improving well-being and Health Status. ${ }^{[9-18,23]}$

Planning care in respect of the individual patient's experience of the situation to a greater extent results in changes in patient behaviours that are regarded as positive for Health Status and preventing disease progression. ${ }^{[24-27]}$ It requires involvement of the patient in the planning of the care process and also that the patient is able to make decisions and to convert knowledge acquired from the provided education to beneficial actions in practice.

Educating patients to manage symptoms and everyday prevention of progression in HF seems to be a cornerstone in self-care management, but it is unclear whether the education should be delivered in groups or individually. ${ }^{[28]}$

In conclusion, it appears essential that interventions are based on education and increased adherence from the patient. Increased adherence is not achieved by education alone but it also depend on the relationship between patient and caregiver. ${ }^{[3,4]}$ Involvement of the patient to ensure adherence seems to be important not only in the out- patient clinic but also in the patient's own setting. ${ }^{[21,22,29]}$ The aim of this study was therefore to test a protocol for rehabilitation of patients after completing rehabilitation in the outpatient clinic. The protocol was based on the principles of Evidence Based Health Care ${ }^{[30-32]}$ and tested the effect of systematic involvement of patients in their rehabilitation in their own home by stimulating increased self-care. Outcomes of the Interventions were Health Status and Self-Care ability.

\section{Methods}

The study included patients from cardiac wards at two teaching hospitals in Zeeland, Denmark. Patients who were 18 years or older and diagnosed with mild to moderate Heart Failure symptoms and who had completed hospital based rehabilitation were included in the study. Patients who declined to participate; patients who did not understand the study information due to mental disorders, language and hearing problems and patients diagnosed with neurological deficits were excluded. Approximately 100-120 patients completed the hospital based rehabilitation program yearly.

\subsection{Design}

The study was a controlled study ${ }^{[33,34]}$ using a quasiexperimental design, with a control group but without randomization. After completing the hospital based rehabilitation program in the period from October 2010 to July 2011 patients were allocated to the control group and after completing their hospital based rehabilitation program in the period from November 2011 to July 2012 patients were allocated to the intervention group.

For all patients Health Status and self-care behavior were measured at inclusion in the study (baseline) and after 4 and 12 weeks.

Patients in the control group were discharged to follow up by their own GPs. Patients in the intervention group were also discharged to follow up by their own GPs combined with a specific nursing rehabilitation protocol carried out by a clinical nurse specialist ("A Clinical Nurse Specialist is prepared at the masters'- or doctorate level as a clinical nurse specialist and is an expert clinician in a specialized area of nursing practice. The specialty may be a population, a setting, a disease or medical subspecialty, a type of care or type of problem" [National Association of Clinical Nurse Specialists, 2004.]) (see Table 1).

\subsection{Sample size}

To achieve sufficient statistical power the sample size was calculated. Type I error: 5\%. The expected effect rate was estimated to $30 \%$ and minimal difference between effect rates not to be overlooked, 30\%. Type II error was estimated to $20 \%$. The calculation was based on expected improvements in self-care. ${ }^{[35]}$ The minimum sample size was 
calculated to be 60 in each group (control and intervention), a total of 120 patients. With an expected drop-out rate at $20 \%, 70$ patients were included in each group. Calculations of drop out and patient numbers are based on power calculation. ${ }^{[24,36]}$

Table 1: Differences in rehabilitation between the control and intervention group

\begin{tabular}{|c|c|c|}
\hline & $\begin{array}{l}\text { Control } \\
\text { Group }\end{array}$ & $\begin{array}{l}\text { Intervention } \\
\text { Group }\end{array}$ \\
\hline Rehabilitation Phase I & Yes & Yes \\
\hline Rehabilitation Phase II & Yes & Yes \\
\hline \multicolumn{3}{|l|}{ Rehabilitation Phase III } \\
\hline \multicolumn{3}{|l|}{ After discharge followed up by: } \\
\hline GP & Yes & Yes \\
\hline $\begin{array}{l}\text { Developing of individual rehabilitation } \\
\text { care plan }\end{array}$ & No & Yes \\
\hline Telephone follow up after 4 weeks & No & Yes \\
\hline Telephone follow up after 12 weeks & No & Yes \\
\hline
\end{tabular}

\subsection{Theoretical frame of reference}

The nursing intervention in this study was based on motivational theories combined with a theory of development in which the main goal is to promote and maintain patients' active involvement in their own care. ${ }^{[25]}$ The model includes four main elements:

(1) Assessing the patient's normal activities in relation to health issues and daily functioning. This assessment is based on motivational theory and theory on subjective and objective press for human activities. ${ }^{[25,37]}$ The central element is the patient's behavior in relation to health, where actual behavior seems determined by the predispositions of the individual, the individual's enabling factors for achieving healthpromoting behavior and, finally, reinforcing factors that stimulate motivation. ${ }^{[25,38]}$

(2) Continued dialogue between patient and nurse, to ensure information sharing, teaching and individual care.

(3) Planning of nursing care with reference to the patient's usual activities of daily living.

(4) Use of the principles embedded in primary nursing care (First author)

This model has been tested in studies including patients suffering from various medical and orthopedic diseases and the findings confirm that patients cared for with this model experienced more personal activity and growth during hospital stay compared to patients receiving usual care. ${ }^{[24]}$

\subsection{Intervention}

When included in the study patients assessed their Health Status and self-care behavior in relation to HF. ${ }^{[39]}$ Based on this assessment the CNS and the patients mutually devel- oped and agreed on an individual care plan with goals for further education and information sharing.

After 4 and 12 weeks the patients filled out and retuned the self-administered questionnaires. Based on the scores and the goals in the care plan, the clinical nurse specialist continued the dialogue with the patient by telephone.

\subsection{Measurements}

Health Status was measured with the Short Form 36 (SF36) ${ }^{[40]}$ and EuroQol (EQ5D) ${ }^{[41]}$ and self-care behavior with the European Heart Failure Self Care Behavior Scale (EHFScBS). ${ }^{[39]}$

SF-36 is a validated tool for measuring Health Status and has been translated into Danish. ${ }^{[40]}$ In the present study, the Internal consistency reliability of the eight SF-36 scales was above 0.70 for all scales. ${ }^{[40]}$ The questionnaire consists of 36 questions, summarized into eight subscales. Four subscales can be combined into an overall measurement of physical health (PCS) and the four subscales can be combined into an overall measurement of mental health $(\mathrm{MH})$ which together produces a rating of overall Health Status. ${ }^{[40]}$ Responses are transformed into a score on a scale from zero (lowest score) to 100 (highest score) with a higher score indicating better Health Status. ${ }^{[40]}$

EuroQol (EQ5D) is translated into Danish and is a generic, validated instrument for measuring Health Status. ${ }^{[41-43]}$ It obtains a rating of self-perceived overall health. ${ }^{[44]}$ The instrument is descriptive and consists of five dimensions measuring the individual's Health Status. The five dimensions are: mobility, self-care, usual activities, pain/discomfort, and anxiety/depression/depression. Responses rate three levels of severity (no problems, moderate problems or extreme problems) within a particular EQ5D dimension. It is combined with a visual analogue scale from zero to one hundred measuring general health perception. EQ5D has been tested in different populations, including patients with cardiovascular disease, with satisfactory validity, reliability and responsiveness. ${ }^{[41,42,45]}$

Self-care behavior was measured with the EHFScBS which is a 12-item, self-administered questionnaire that covers items concerning self-care behavior of Heart Failure patients, with a high reliability. Face-validity, concurrent validity has been established, and the internal consistency of the scale has been tested and shows Cronbach's alpha $0.81 .^{[39]}$ The instrument is a valid, reliable and practical scale to measure the self-reported self-care behavior of $\mathrm{HF}$ patients ${ }^{[39]}$ based on the aspects of self-care EHFScBS measures behavior that maintains self-care. In this context selfcare is defined as the decisions and strategies undertaken by the individual in order to maintain life, healthy functioning and well-being. ${ }^{[39]}$ EHFScBS measures compliance with medical regimens, observation of edema, the ability to respond adequately to observed progression in $\mathrm{HF}$ and ad- 
just daily activities in accordance with current physical abilities. Each item is scored on a 5-point Likert scale. The patient can obtain a score between 12 and 60 points, where 12 points indicates a very high self-care behavior and 60 points a very low self-care behavior. A total score is calculated by summing all items as recommended by Jarsmaa, et al. ${ }^{[39]}$ If more than three items were missing the total score was not obtained. In case of three missing items the value three was used to replace the missing score per item. ${ }^{[39,46]}$ Cronbach's alpha in this study was 0.81 .

Scores were calculated on self-perceived overall health using the forms from EuroQol secretary. ${ }^{[47]}$ Heart Failure was clarified by a cardiologist using the New York Heart Failure scale (NYHA) ${ }^{[48]}$ The cardiologist was blinded for the allocation of the patients to the interventions or control group.

Information on gender, age, marital status, dependence of help, was self-reported by patients. We obtained Information on weight and height from the patients' medical records.

\subsection{Ethical considerations}

Patients were included in the study after giving informed consent. They were ensured that they could withdraw from the study at any time without any consequences for their further treatment. The experiment are reported to the research ethics committee (2013-41-1935), Danish Data Surveillance Authorities and www.clinicaltrial.gov (NCT01239667).

\subsection{Stastictics}

Data were analyzed using SPSS version 20. ${ }^{[49]}$ Ratio-scale data from both groups were tested by F-test for distribution. Normally distributed data were compared by the Student's t test. Nominal scale data were compared by chi-square tests or by the use of the $95 \%$ confidence intervals. ${ }^{[36]}$ All calculations were based on "intention to treat" analysis. ${ }^{[50,51]}$ Cronbach's alpha was used to assess the reliability of the questionnaires used in the study. Level of significance was set at $p<.05$.

Missing data were replaced by mean scores where possible and by last observation carried forward where mean scores were not available within the control and intervention groups respectively. ${ }^{[51-53]}$ We used logistic regression analysis to examine variables associated with increased selfcare. Pearson's correlation analyse were carried out in order to tests for correlations between ratio scale data.

\section{Results}

A total of 162 patients were included in the study of whom $137(84.6 \%$ ) completed the study (see Figure 1). The groups were similar with regard to gender, age, NYHA classes', body mass index, living alone and dependence on help (see Table 2). Drop out analysis showed no differences between those who withdrew from the study and those who completed the study in relation to demographic variables $(p=$ $.106-.907)$.

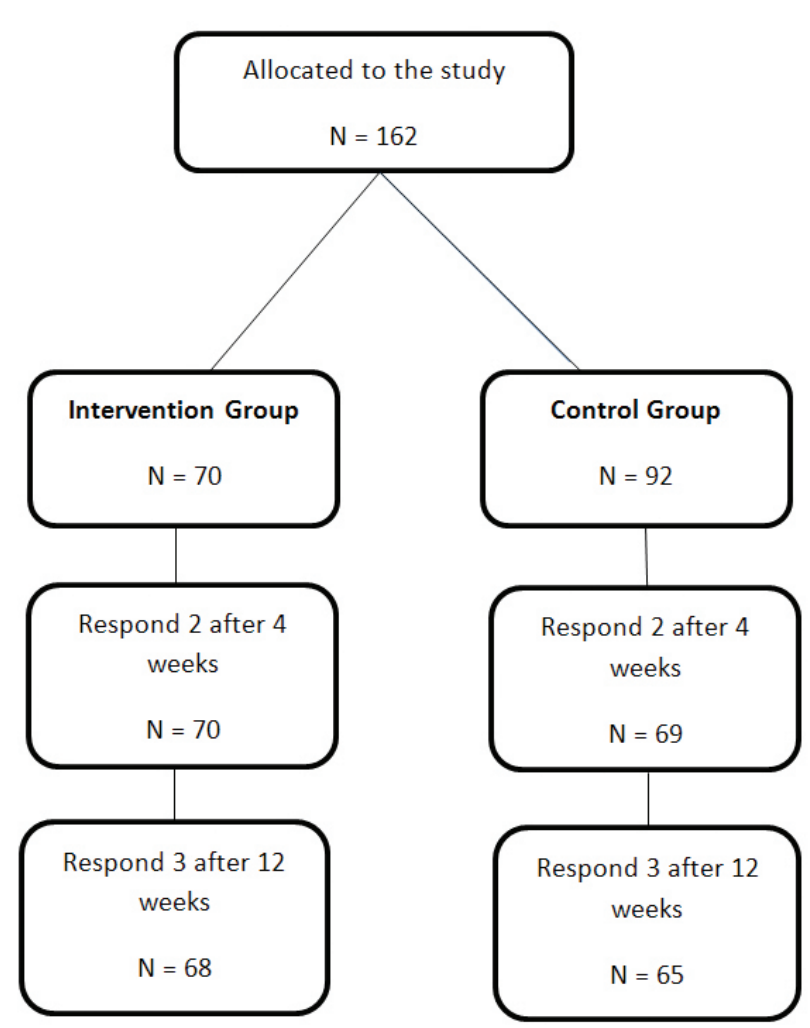

Figure 1: Flow chart

There were no difference in total self-care behavior between the groups at baseline $(p=.161)$. After four weeks the total self-care score for the control group was $25.3 \mathrm{vs} .22 .2$ in the intervention group $(p=.049)$. After twelve weeks the self-care score in the control group was 26.8 vs. 22.6 in the intervention group $(p=.007)$ (see Table 3$)$. The frequency of patients in the control vs. the interventions group, who had a positive change in self-care score from baseline to four weeks after allocation to phase 3 rehabilitation was $37 \%$ vs. $73 \%(p<.000)$, and twelve weeks after baseline the frequency of patients who had a positive changes in self-care scores were reported to be $33 \%$ in the control group vs. $69 \%$ in the intervention group $(p=.000)$.

Changes in total SF-36 were analyzed in subgroups related to gender, degree of HF, marital status or dependency of help in daily living from baseline to three month after inclusion in the study. No differences were detected in changes in the total score either in the control or the interventions group (see Table 3). No correlation between age and changes in total self-care score were detected in either the control or intervention croup $(r=-.118, r=-.190)$ 
Table 2: Baseline characteristics of participating patients

\begin{tabular}{lllc}
\hline & $\begin{array}{l}\text { Control } \\
\text { N = 92 }\end{array}$ & $\begin{array}{l}\text { Intervention } \\
\mathbf{N = 7 0}\end{array}$ & $\boldsymbol{p}$ \\
\hline Gender & & & \\
Male N (\%) & $68(73.9)$ & $49(70)$ & 0.600 \\
Female N (\%) & $24(26 ., 1)$ & $21(30)$ & \\
Age & & & \\
Mean (SD) & $67.8(10.8)$ & $66.3(11.3)$ & 0.833 \\
(min.-max.) & $(37-89)$ & $(39-89)$ & \\
NYHA & & & \\
Class II & $67(72,8)$ & $56(80)$ & 0.355 \\
Class III & $25(27.2)$ & $14(20)$ & \\
BMI kg/m ${ }^{2}$ (SD) & $27.7(5.1)$ & $27.6(5.2)$ & 0.759 \\
(min.-max.) & $(15.6-46.4)$ & $(18.2-46.2)$ & \\
Living alone & & & 1.0 \\
Yes N (\%) & $19(20.7)$ & $15(21.5)$ & \\
No N (\%) & $73(79.3)$ & $55(78.6)$ & \\
Dependent of help & & & \\
Yes N (\%) & $13(14.1)$ & $9(12.9)$ & \\
No N (\%) & $79(85.9)$ & $61(89.1)$ & \\
\hline
\end{tabular}

Patient's scores in EQ5D scores are presented in Table 3. Total EQ5D scores showed no significant differences between the groups at baseline (see Table 3). Subgroup analyses showed a significant difference in usual activities in the intervention group with a within-group increase from 34.4 percent at baseline to 51.4 percent after 12 weeks ( $p$ $=.0002$ ). Similarly, anxiety/depression decreased significantly within the intervention group from baseline to followup. We found no between-groups differences at 1 month or 3 months.

Both the control and intervention groups reported lower within-groups scores at 12 weeks compared to baseline (see Table 4). The within group scores in the control group declined with a mean of 0.14 (and in the intervention group with a mean of $0.06(p=.014)$

We performed a binary logistic regression analysis to examine associations between the number of patients reporting anxiety after 12 weeks and group allocation, difference in Self-care from base line to 12 weeks; age; dependent of help; NYHA and weight (see Table 5). The results showed a significant association between "binary outcome" and being in the intervention group $(p=.001)$ difference in self-care $(p=.045)$ and age. No significant results for the other items showed changes between or within groups from baseline to twelve weeks.

\section{Discussion}

Significantly higher within-group scores were found in total self-care behavior in the intervention group after twelve weeks, and subgroup-analyses showed significantly reduced development of anxiety. The intervention group and the control group were similar regarding demographic variables, such as age, gender, living alone and dependency on help, NYHA classes and self-care behavior at inclusion in the study. These factors are also factors that might interact with the patients' health status on an individual level. Therefore, patients need suggestions to cope with the consequences for in order to achieve a positive outcome of the rehabilitation. As the binary logistic regression analysis identified that being in the intervention group had the strongest association for preventing developing of anxiety during the rehabilitation period this might suggest that the intervention had been truly individualized.

In a systematic review based on 35 studies $^{[18]}$ subgroup analysis has not been carried out. Therefore it can be difficult to evaluate whether individualizing was truly carried out and difficult to compare our results with others.

Furthermore we found that patients rated their Health Status to be moderate (scoring range from 0 to 100). The physical and emotional dimensions of Health Status were also in the middle of the possible scoring ranges. The Health Status score had a large SD of 25, indicating that the patients had a highly variable Health Status.

According to Total EQ5D scores there were no significant differences between the groups at follow-up. However, it is interesting that we found an increase in scores on usual activities and a reduction in the number of patients' with anxiety/depression at 12 weeks in the intervention group. In the logistic regression analysis we found a significant association between reduction in anxiety/depression and being in the intervention group $(\mathrm{OR}=.324, \mathrm{CI}=.112-.555)(p=$ $.01)$ and increased self-care behavior $(\mathrm{OR}=.468, \mathrm{CI}=.199$ $-.983, p=.045)$. This association indicates a possible beneficial effect of the intervention. After phase two of the rehabilitation, patients are transferred to continued rehabilitation in their own municipality. Our intervention indicates that having access to a healthcare professional may reduce the number of patients who develop anxiety/depression. Evidence to support a link between self-care in patients with HF and health outcomes is limited. ${ }^{[19,54]}$ The results from our study are in line with the results from the study by Tung, et $a l .{ }^{[19]}$ Furthermore we found a correlation between self-care behavior and reduced anxiety/depression. It has previously been asserted that there is a clear relationship between depression and poor Health Status, a relationship which seems to be associated with poor self-care. ${ }^{[55]}$ To our knowledge this is one of the first studies which have actually shown this possible correlation.

\subsection{Limitations}

In an Evidence based health care practice we work with the elements of Best available evidence, patients prefer- 
ences and available professional skills, expertise and clinical judgment. ${ }^{[30]}$ The Randomized Controlled trial (RCT) is considered to be the strongest design in testing hypotheses, due to the randomized allocation of patients and control over the experimental situation which includes control group and manipulation according to whether the patient receives treatment or not. An important issue is, that optimally patients as well as staff should be blinded. ${ }^{[56-58]}$ Blinding is an important part of a RCT. If blinding is inadequate, results may be biased. [59] The main goal of our study was to generate the best possible evidence for an effect of an individualized rehabilitation intervention for patients with HF. In our study we did not judge it possible to blind patients or investigators due to the nature of the intervention.

Table 3: Self-care behavior scores, EQ5D scores and functional scores SF-36

\begin{tabular}{|c|c|c|c|}
\hline & Control & Intervention & $p$ \\
\hline \multicolumn{4}{|c|}{ Self-care behavior Total score (SD) } \\
\hline Baseline & $26.5(8.0)$ & $28.4(7.2)$ & .161 \\
\hline After 4 weeks & $25.3(7.4)$ & $22.2(7.7)$ & .049 \\
\hline After 12 weeks & $26.8(8.9)$ & $22.6(8.2)$ & .007 \\
\hline \multicolumn{4}{|c|}{ EQ5D Total score (SD) } \\
\hline Baseline & $.81(.14)$ & $.78(.16)$ & .2 \\
\hline After 4 weeks & $.8(.15)$ & $.8(.16)$ & .55 \\
\hline After 12 weeks & $.66(.22)$ & $.71(.22)$ & .21 \\
\hline \multicolumn{4}{|c|}{ Functional scores SF 36 (SD) } \\
\hline \multicolumn{4}{|c|}{ PCS } \\
\hline Baseline & $39.31(9.6)$ & $41.24(9.5)$ & .207 \\
\hline After 4 weeks & $40.7(8.9)$ & $41.2(8.8)$ & .738 \\
\hline After 12 weeks & $40.0(10.6)$ & $40.3((9.5)$ & .838 \\
\hline \multicolumn{4}{|l|}{ MCS } \\
\hline Baseline & $49.8(9.5)$ & $47.9(9.3)$ & .214 \\
\hline After 4 weeks & $48.0(11.9)$ & $50.1(8.8)$ & .276 \\
\hline After 12 weeks & $49.6(9.1)$ & $48.2(9.4)$ & .364 \\
\hline
\end{tabular}

In this study we consecutively included patients first in the control group, and afterwards in the intervention group. We did this to eliminate the risk of contamination between the groups and to minimize the risk of performance bias caused by ward staff. Patients in the study corresponded to the patient population in Denmark with regard to gender, age and diagnosis at admission. Thus, the patient group in the study represented patients discharged after admission for HF. The patients who did not participate were no different from those participating in terms of age and gender. The criteria for inclusion enhanced the probability of a homogeneous study group in respect to diagnoses and treatment. Number of patients needed was calculated and the consecutive allocation to the study eliminated that differences would be due to differences in co-morbidity in population. The rehabilitation program and treatment of the patients in the hospital part was not changed during the study period. Health Status was recorded and calculated for patients in both the intervention and control group. In order not to affect the treatment, transferring results to subscales and calculations were not done until the end of the study. Quasi-experimental studies are vulnerable to confounding. ${ }^{[60]}$ This entails that the groups may be unequal due to unknown factors affecting exposure/intervention and outcomes. Therefore causal rela36 tionships cannot be determined in this type of study.

\subsection{Strengths}

The strength of the study is that validated tools were used, ${ }^{[39-41]}$ and that the Danish SF-36 seems to be the best to use among people with chronic diseases, in terms of reliability, and the discriminatory power of the instrument. ${ }^{[40]}$ It was developed as a short-form measure of functioning and well-being in the Medical Outcomes Study ${ }^{[61]}$ which matches the goal in our study.

Drop out is well known, and in similar studies the dropout rate is described to be between $15 \%-50 \% .^{[24,62]}$ In this study the dropout rate was $17.3 \%$. The drop out analysis showed, that there were no differences between patients who dropped out of the study and patients who completed the study in relation to demographic data. There were a higher number of dropouts from the control group than from the intervention group, which may be due to the fact that control patients did not receive telephone follow up after 1 and 3 months. Telephone follow up after 1 and 3 month may in itself motivate patients to continue in the intervention group. ${ }^{[24]}$ 
Table 4: EQ5D scores

\begin{tabular}{|c|c|c|c|c|c|c|}
\hline & \multicolumn{2}{|c|}{ Baseline } & \multicolumn{2}{|c|}{4 weeks } & \multicolumn{2}{|c|}{12 weeks } \\
\hline & $\begin{array}{l}\text { Control } \\
\mathrm{n}=92(\%)\end{array}$ & $\begin{array}{l}\text { Intervention } \\
\mathbf{n}=\mathbf{7 0}(\%)\end{array}$ & $\begin{array}{l}\text { Control } \\
\mathrm{n}=92(\%)\end{array}$ & $\begin{array}{l}\text { Intervention } \\
\mathbf{n}=\mathbf{7 0}(\%)\end{array}$ & $\begin{array}{l}\text { Control } \\
\mathrm{n}=92(\%)\end{array}$ & $\begin{array}{l}\text { Intervention } \\
\mathbf{n}=\mathbf{7 0}(\%)\end{array}$ \\
\hline \multicolumn{7}{|l|}{ Mobility } \\
\hline I have no problems in walking about & $51(55.4)$ & $46(65.7)$ & $58(63)$ & $46(65.7)$ & $64(69.6)$ & $46(65.7)$ \\
\hline I have some problems in walking about & $41(44.6)$ & $24(34.3)$ & $34(37.0)$ & $24(34.3)$ & $28(30.4)$ & $24(34.3)$ \\
\hline I am confined to bed & $0(0)$ & $0(0)$ & $0(0)$ & $0(0)$ & $0(0)$ & $0(0)$ \\
\hline \multicolumn{7}{|l|}{ Self-care } \\
\hline I have no problems with self-care & $81(88.0)$ & $66(94.3)$ & $82(89.1)$ & 65 (92.9) & 79 (85.5) & $66(94.3)$ \\
\hline $\begin{array}{l}\text { I have some problems washing or dressing } \\
\text { myself }\end{array}$ & $11(12.0)$ & $4(5.7)$ & 10 (10.9) & $5(7.1)$ & $13(14.1)$ & $4(5.7)$ \\
\hline I am unable to wash or dress myself & $0(0)$ & $0(0)$ & $0(0)$ & $0(0)$ & $0(0)$ & $0(0)$ \\
\hline $\begin{array}{l}\text { I have no problems with performing my usual } \\
\text { activities }\end{array}$ & $46(50.0)$ & $34(34.4)$ & 45 (48.9) & 30 (42.9) & $47(51.1)$ & $36(51.4)^{*}$ \\
\hline $\begin{array}{l}\text { I have some problems with performing my } \\
\text { usual activities }\end{array}$ & $44(47.8)$ & $38(54.3)$ & $40(43.5)$ & $31(44.3)$ & $39(42.4)$ & 39 (42.9) \\
\hline I am unable to perform my usual activities & $2(2.2)$ & $8(11.4)$ & $7(7.6)$ & 9 (12.9) & $6(6.5)$ & $4(5.7)$ \\
\hline \multicolumn{7}{|l|}{ Pain/Discomfort } \\
\hline I have no pain or discomfort & $49(53.3)$ & $36(51.4)$ & $46(50.0)$ & $39(55.7)$ & $41(44.6)$ & $38(54.3)$ \\
\hline I have moderate pain or discomfort & $42(45.7)$ & 30 (42.9) & $44(47.8)$ & $29(45.1)$ & $49(53.3)$ & 30 (42.9) \\
\hline I have extreme pain or discomfort & $1(1.1)$ & $4(5.7)$ & $2(2.2)$ & $2(2.9)$ & $2(2.2)$ & $2(2.9)$ \\
\hline \multicolumn{7}{|l|}{ Anxiety/Depression } \\
\hline I am not anxious or depressed & $69(75.0)$ & $51(72.9)$ & $65(70.7)$ & $47(67.1)$ & $54(58.7)$ & $57(81.4)^{*}$ \\
\hline
\end{tabular}

"Significant increase in intervention group related to usual activities and anxiety

Table 5: Results of regression analysis

\begin{tabular}{|c|c|c|c|c|c|c|c|c|}
\hline \multicolumn{9}{|c|}{ Variables in the Equation } \\
\hline \multirow{2}{*}{ Anxiety } & \multirow{2}{*}{ B } & \multirow{2}{*}{ S.E. } & \multirow{2}{*}{ Wald } & \multirow{2}{*}{ df } & \multirow{2}{*}{ Sig. } & \multirow{2}{*}{$\operatorname{Exp}(B)$} & \multicolumn{2}{|c|}{ 95\% CI for EXP(B) } \\
\hline & & & & & & & Lower & Upper \\
\hline Group & -1.391 & .409 & 11.565 & 1 & .001 & .249 & .112 & .555 \\
\hline Self care & -.817 & .408 & 4.007 & 1 & .045 & .442 & .199 & .983 \\
\hline Age & -.037 & .019 & 3.937 & 1 & .047 & .963 & .928 & 1.000 \\
\hline Dependent of help & -.938 & .533 & 3.096 & 1 & .079 & .391 & .138 & 1.113 \\
\hline NYHA & .195 & .453 & .185 & 1 & .667 & 1.215 & .500 & 2.955 \\
\hline Weight & -.028 & .011 & 5.971 & 1 & .015 & .972 & .951 & .994 \\
\hline Constant & 5.239 & 2.123 & 6.089 & 1 & .014 & 188.539 & & \\
\hline
\end{tabular}

\section{Conclusion}

We found no significant increase in Health Status between the groups. Subgroup analysis showed a significant within group decrease in development of anxiety in the intervention group from baseline to twelve weeks. There may be a correlation between the increase in self-care behavior in patients in the intervention group after 12 weeks and a reduction in

Published by Sciedu Press anxiety.

\subsection{Implications for further research}

Further research is needed especially to detect the level of Anxiety/depression and its relation to level of self-care behavior. We suggest a cluster randomized design for future research. 


\subsection{Implications for practice}

This intervention is cheap and can be recommended to primary and community care settings to avoid patient anxi- ety/depression and to stimulate an increase in the ability to perform usual activities of daily living.

\section{References}

[1] Hogg K, Swedberg K, McMurray J. Heart failure with preserved left ventricular systolic function: epidemiology, clinical characteristics, and prognosis. Journal of the American College of Cardiology. 2004; 43: 317-27. PMid:15013109. http://dx.doi.org/10.10 $16 / j \cdot j$ acc.2003.07.046

[2] Ko DT. Life expectancy after an index hospitalization for patients with heart failure: a population-based study. The American heart journal. 2008; 155: 324-31. PMid:18215604. http://dx.doi.o $\mathrm{rg} / 10.1016 / \mathrm{j} \cdot \mathrm{ahj} .2007 .08 .036$

[3] Dickstein K, Cohen-Solal A, Filippatos G, et al. ESC Guidelines for the diagnosis and treatment of acute and chronic heart failure 2008: The Task Force for the Diagnosis and Treatment of Acute and Chronic Heart Failure 2008 of the European Society of Cardiology. Developed in collaboration with the Heart Failure Association of the ESC (HFA) and endorsed by the European Society of Intensive Care Medicine (ESICM). European Journal of Heart Failure. 2008; 10: 933-89. PMid:18826876. http://dx.doi.org/10.10 $16 / j$.ejheart. 2008.08.005

[4] McMurray JJV. ESC Guidelines for the diagnosis and treatment of acute and chronic heart failure 2012: The Task Force for the Diagnosis and Treatment of Acute and Chronic Heart Failure 2012 of the European Society of Cardiology. Developed in collaboration with the Heart Failure Association (HFA) of the ESC. European heart journal. 2012; 33: 1787-847. PMid:22611136. http: //dx.doi.org/10.1093/eurheartj/ehs104

[5] Ryden L. ESC Guidelines on diabetes, pre-diabetes, and cardiovascular diseases developed in collaboration with the EASD: The Task Force on diabetes, pre-diabetes, and cardiovascular diseases of the European Society of Cardiology (ESC) and developed in collaboration with the European Association for the Study of Diabetes (EASD). European heart journal. 2013.

[6] Krum H. 2011 update to National Heart Foundation of Australia and Cardiac Society of Australia and New Zealand Guidelines for the prevention, detection and management of chronic heart failure in Australia, 2006. Medical journal of Australia. 2011; 194: 405-9. PMid:21495941.

[7] McKelvie RS, Moe GW, Ezekowitz JA, et al. The 2012 Canadian Cardiovascular Society Heart Failure Management Guidelines Update: Focus on Acute and Chronic Heart Failure. Canadian Journal of Cardiology. 2013; 29: 168-81. PMid:23201056. http://dx.d oi.org/10.1016/j.cjca.2012.10.007

[8] Heart Failure Society of A. HFSA 2010 Comprehensive Heart Failure Practice Guideline. Journal of cardiac failure. 2010; 16: e1e2. PMid:20610207. http://dx.doi.org/10.1016/j.cardfai 1.2010 .04 .004

[9] McAlister FA, Stewart S, Ferrua S, McMurray JJJV. Multidisciplinary strategies for the management of heart failure patients at high risk for admission: A systematic review of randomized trials. Journal of the American College of Cardiology. 2004; 44: 810-9. PMid:15312864.

[10] Holland R. Systematic review of multidisciplinary interventions in heart failure. Heart (British Cardiac Society). 2005; 91: 899906. PMid:15958358. http://dx.doi.org/10.1136/hrt.200 4.048389

[11] Maric B, Kaan A, Ignaszewski A, Lear SA. A systematic review of telemonitoring technologies in heart failure. European Journal of
Heart Failure. 2009; 11: 506-17. PMid:19332417. http://dx.doi .org/10.1093/eurjhf/hfp036

[12] Inglis SC, Clark RA, McAlister FA, Stewart S, Cleland JG. Which components of heart failure programmes are effective? A systematic review and meta-analysis of the outcomes of structured telephone support or telemonitoring as the primary component of chronic heart failure management in 8323 patients: Abridged Cochrane Review. Eur J Heart Fail. 2011; 13: 1028-40. PMid:21733889. http://dx.doi.org/10.1093/eurjhf/hfr039

[13] Boyde M. Educational interventions for patients with heart failure: a systematic review of randomized controlled trials. The Journal of cardiovascular nursing. 2011; 26: E27-35. PMid:21076308. http://dx.doi.org/10.1097/JCN.0b013e3181ee5fb2

[14] Chaudhry SI, Mattera JA, Curtis JP, et al. Telemonitoring in Patients with Heart Failure. New England Journal of Medicine. 2010; 363: 2301-9. PMid:21080835. http://dx.doi.org/10.1056/NEJMo a1010029

[15] Kent Bea. A systematic review of the effectiveness of current interventions to assist adults with heart failure to comply with therapy and enhance self-care behaviours. JBI Library of Systematic Reviews JBL000364. 2011.

[16] Barnason S. An integrative review of interventions promoting selfcare of patients with heart failure. Journal of Clinical Nursing. 2012; 21: 448-75. PMid:22098479. http://dx.doi.org/10.1111/j $.1365-2702.2011 .03907 . x$

[17] Takeda A, Taylor Stephanie JC, Taylor Rod S, Khan F, Krum $\mathrm{H}$, Underwood M. Clinical service organisation for heart failure. Cochrane database of systematic reviews. 2012. PMid:22972058. http://dx.doi.org/10.1002/14651858.CD002752.pub3

[18] Wakefield BJ. Heart failure care management programs: a review of study interventions and meta-analysis of outcomes. The Journal of cardiovascular nursing. 2013; 28: 8-19. PMid:22343208. http://dx.doi.org/10.1097/JCN.0b013e318239f9e1

[19] Tung H-H, Lin C-Y, Chen K-Y, Chang C-J, Lin Y-P, Chou C-H. SelfManagement Intervention to Improve Self-Care and Quality of Life in Heart Failure Patients. Congestive Heart Failure. 2012.

[20] Jaarsma T, Strömberg A, Ben Gal T, et al. Comparison of self-care behaviors of heart failure patients in 15 countries worldwide. Patient Education and Counseling. 2013. http://dx.doi.org/10.1016 $/ j$.pec.2013.02.017

[21] Van der Wal MHL, Jaarsma T, van Veldhuisen DJ. Non-compliance in patients with heart failure; how can we manage it? European Journal of Heart Failure. 2005; 7: 5-17. PMid:15642526. http: //dx.doi.org/10.1016/j.ejheart.2004.04.007

[22] Evangelista LS, Dracup K. A Closer Look at Compliance Research in Heart Failure Patients in the Last Decade. Progress in Cardiovascular Nursing. 2000; 15: 97-103. PMid:10951951. http://dx.d oi.org/10.1111/j.1751-7117.2000.tb00212.x

[23] Ditewig JB, Blok H, Havers J, Van Veenendaal H. Effectiveness of self-management interventions on mortality, hospital readmissions, chronic heart failure hospitalization rate and quality of life in patients with chronic heart failure: A systematic review. Patient Education and Counseling. 2010; 78: 297-315. PMid:20202778. http://dx.doi.org/10.1016/j.pec.2010.01.016

[24] Hørdam B, Sabroe S, Pedersen PU, Mejdahl S, Søballe K. Nursing intervention by telephone interviews of patients aged over 65 years after total hip replacement improves health status: a randomised clinical trial. Scandinavian Journal of Caring Sciences. 2010; 24: 94-100. PMid:19422632. http://dx.doi.org/10.1111/j.147 $1-6712.2009 .00691 . x$ 
[25] Pedersen PU. Nutritional care: the effectiveness of actively involving older patients. Journal of Clinical Nursing. 2005; 14: 247 55. PMid:15669934. http://dx.doi.org/10.1111/j.1365-2 702.2004.00874. $\mathrm{x}$

[26] Pedersen PU. Stimmulation til sufficient kostindtagelse - effekten af at medinddrage ældre ortopædkirurgiske patienter i egen. kostforplejning. Ph.D afhandling Syddansk Universitet. 2000. [Stimmulation to sufficient dietary intake - the effectkt of actively involving the older orthopædic patient in own dietary intake. Thesis University of South Denmark. 2000.]

[27] Salling Larsen AL. Stimmulation af patientens aktivitet og udvikling. Odense University. 1990. [Stimmulation of the patients aktivity and developing. Odense University. 1990.] PMid:2075609.

[28] Barlow J, Wright C, Sheasby J, Turner A, Hainsworth J. Selfmanagement approaches for people with chronic conditions: a review. Patient Education and Counseling. 2002; 48: 177-87. http: //dx.doi.org/10.1016/S0738-3991 (02) 00032-0

[29] Evangelista LS. What do we know about adherence and selfcare? The Journal of cardiovascular nursing. 2008; 23: 2507. PMid:18437067. http://dx.doi.org/10.1097/01. JCN.00 $00317428.98844 .4 \mathrm{~d}$

[30] Pearson A, Wiechula R, Court A, Lockwood C. The JBI model of evidence-based healthcare. International Journal of Evidence-Based Healthcare. 2005; 3: 207-15. PMid:21631749.

[31] Sackett DL SS, Richardson S, Rosenberg W, Haynes RB. Evidencebased medicine: how to practice and teach EBM. London, : U.K. Churchill Livingstone, 2000.

[32] Sackett DL. Evidence based medicine: what it is and what it isn't. BMJ British medical journal (Clinical research ed). 1996; 312: 71-2. http://dx.doi.org/10.1136/bmj .312.7023.71

[33] Harmon RJ, Morgan GA, Gliner JA, Harmon RJ. QuasiExperimental Designs. Journal of the American Academy of Child and Adolescent Psychiatry. 2000; 39: 794-6. PMid:10846316. ht tp://dx.doi.org/10.1097/00004583-200006000-00020

[34] Lynda S. Robson HSS, Linda M. Goldenhar, Andrew R. Hale Quasiexperimental and experimental designs: more powerful evaluation designs. Institute for Work \& Health, Canada, 2001.

[35] Jaarsma TPRNa, Halfens RPa, Tan FPb, Abu-Saad HHPa, Dracup KDRNc, Diederiks JPd. Self-care and quality of life in patients with advanced heart failure: The effect of a supportive educational intervention. Heart \& Lung: Journal of Acute \& Critical Care September/October. 2000; 29: 319-30. PMid:10986526. http://dx.doi . org $/ 10.1067 / \mathrm{mhl} .2000 .108323$

[36] Kirkwood BR. Medical Stastictics. 2rd. ed. Blackwell Science Ltd.; 2003.

[37] Larsen AS. Helping patients avoid readmission to hospital: a health behaviour study. Recent Adv Nurs. 1988; 22: 62-88. PMid:3231735.

[38] Green LW, Kreuter MW. Health promotion planing - An educational and enviromental approach. Mountain View: Maryfield Publishing Company; 1991

[39] Jaarsma T. Development and testing of the European Heart Failure Self-Care Behaviour Scale. European Journal of Heart Failure. 2003; 5: 363-70. http://dx.doi.org/10.1016/S1388-9 $842(02) 00253-2$

[40] Bjorner JB, Damsgaard MT, Watt T, Groenvold M. Tests of Data Quality, Scaling Assumptions, and Reliability of the Danish SF36. Journal of clinical epidemiology. 1998; 51: 1001-11. http: //dx.doi.org/10.1016/S0895-4356 (98) 00092-4

[41] Rabin R, Rabin R. EQ-5D: a measure of health status from the EuroQol Group. Annals of medicine (Helsinki). 2001; 33: 337-43. http://dx.doi.org/10.3109/07853890109002087

[42] Hurst NP, Kind P, Ruta D, Hunter M, Stubbings A. Measuring health-related quality of life in rheumatoid arthritis: validity, responsiveness and reliability of EuroQol (EQ-5D). Rheumatology. 1997; 36: 551-9. http://dx.doi.org/10.1093/rheumatolog $\mathrm{y} / 36.5 .551$

[43] Brooks R. EuroQol: the current state of play. Health Policy. 1996; 37: 53-72. http://dx.doi.org/10.1016/0168-8510(96)008 $22-6$
[44] Pihl E, Cider Å, Strömberg A, Fridlund B, Mårtensson J. Exercise in Elderly Patients with Chronic Heart Failure in Primary Care: Effects on Physical Capacity and Health-Related Quality of Life. European Journal of Cardiovascular Nursing. 2011; 10: 1508. PMid:21470913. http://dx.doi.org/10.1016/j.ejcnurs e. 2011.03 .002

[45] Dyer MT. A review of health utilities using the EQ-5D in studies of cardiovascular disease. Health Qual Life Outcomes. 2010; 8: 13. PMid:20109189. http://dx.doi.org/10.1186/1477-7 525-8-13

[46] Jaarsma T, Årestedt KF, Mårtensson J, Dracup K, Strömberg A. The European Heart Failure Self-care Behaviour scale revised into a nine-item scale (EHFScB-9): a reliable and valid international instrument. European Journal of Heart Failure. 2009; 11: 99105. PMid:19147463. http://dx.doi.org/10.1093/eurjhf/ hfn007

[47] EuroQol Group Association. About EQ5D. Avaiable from: http: //www. euroqol.org/about-eq-5d.html.

[48] American Heart Association. Classes of Heart Failure. Avaiable from: http://www.abouthf.org/questions_stages.htm.

[49] Nielsen T, Kreiner, S. SPSS Introduktion til databehandling \& Statistisk analyseSPSS Jurist - og Økonomforbundets Forlag., 2003. [Introduction to databehandling \& stastistck analyse. Jurist - og Økonomforbundets Forlag., 2003.]

[50] Soares I. Intention to treat analysis in clinical trials: principles and practical importance. Revista portuguesa de cardiologia. 2002; 21: 1191-8. PMid:12522981.

[51] Armijo-Olivo S, Warren S, Magee D. Intention to treat analysis, compliance, drop-outs and how to deal with missing data in clinical research: a review. Physical therapy reviews. 2009; 14: 36-49. http://dx.doi.org/10.1179/174328809X405928

[52] Intention to treat analysis and per protocol analysis: complementary information. Prescrire international. 2012; 21: 304-6. PMid:23373104.

[53] Polit DF. The use of the intention-to-treat principle in nursing clinical trials. Nursing research (New York). 2009; 58: 3919. PMid:19918150. http://dx.doi.org/10.1097/NNR.0b013 e3181bf 1505

[54] Medscape B. Self care in patients with chronic heart failure. Nature reviews cardiology. 2011; 8: 644-54. PMid:21769111. http: //dx.doi.org/10.1038/nrcardio. 2011.95

[55] Widdershoven J, Kessing D, Schiffer A, Denollet J, Kupper N. How are Depression and Type D Personality Associated with Outcomes in Chronic Heart Failure Patients? Current heart failure reports. 2013; 10: 244-53. PMid:23661199. http://dx.doi.org/10.10 07/s11897-013-0139-7

[56] Miettinen O. Confounding and effect-modification. 1974. American journal of epidemiology. 1995; 141: 1113-6 discussion 1-2. PMid:7771449.

[57] Kunz R. Randomisation to protect against selection bias in healthcare trials. Cochrane database of systematic reviews. 2007: MR000012. PMid:17443633.

[58] Odgaard-Jensen J, Vist Gunn E, Timmer A, et al. Randomisation to protect against selection bias in healthcare trials. Cochrane database of systematic reviews. 2011. PMid:21491415. http://dx.doi.o $\mathrm{rg} / 10.1002 / 14651858$. MR000012.pub3

[59] Feys F. Do randomized clinical trials with inadequate blinding report enhanced placebo effects for intervention groups and nocebo effects for placebo groups? Systematic reviews. 2014; 3: 14.

[60] DiNardo J. natural experiments and quasi-natural experiments. In: Durlauf SN and Blume LE, (eds.). The New Palgrave Dictionary of Economics. Basingstoke: Palgrave Macmillan; 2008.

[61] Coons S, Rao S, Keininger D, Hays R. A Comparative Review of Generic Quality-of-Life Instruments. PharmacoEconomics. 2000; 17: 13-35. PMid:10747763. http://dx.doi.org/10.2165/000 19053-200017010-00002

[62] Bell ML, Kenward MG, Fairclough DL, Horton NJ. Differential dropout and bias in randomised controlled trials: when it matters and when it may not. BMJ. 2013; 346. 